\title{
TRADUÇÕES COLABORATIVAS: O CASO DAS FANFICTIONS
}

\author{
Fabíola Reis \\ Universidade Federal do Amapá, AP \\ Izabela Leal $^{* *}$ \\ Universidade Federal do Pará, PA \\ Christiane Stallaert ${ }^{* * *}$ \\ Universiteit Antwerpen, BEL
}

Resumo

Este artigo apresenta os resultados de uma pesquisa sobre a tradução voluntária e colaborativa de fanfictions, histórias escritas por fãs, presentes com maior ocorrência nos últimos anos na Internet. Embora a tradução colaborativa não seja um fenômeno novo, tendo sido documentada na história da tradução no Ocidente e nas culturas não ocidentais, na era digital esta forma de traduzir ganha novas dimensões. Duas traduções de fanfictions, Palavras com Estranhos (no original, Words with Strangers, de Nolebucgrl, uma autora de fanfictions) e Palavras com Amigos (Words with Friends, da mesma autora), realizadas por um grupo de tradutoras no Brasil servirão como exemplos para salientar algumas características da tradução colaborativa de fanfictions realizada na Internet. A pesquisa revela o caráter coletivo da prática tradutória, elaborada e publicada online por tradutoras femininas não profissionais. Nossa análise destaca o trabalho em "cadeia”, a interação entre tradutores e leitores, e o processo de elaboração marcado por tempos específicos que resultam dessa dupla interação: entre as tradutoras, por um lado, e entre tradutor-leitor, por outro.

Palavras-chave: Fanfictions ; Tradução Colaborativa; Tradução Online.

\section{Abstract}

This article presents the results of a research on voluntary and collaborative translation of fanfictions (stories written by fans), which have figured with higher incidence on the Internet in recent years. Although collaborative translation is not a new phenomenon and has been documented in the

\footnotetext{
* Doutora em Estudos Literários (UFPA) e em Estudos da Tradução (Universiteit Antwerpen), professora adjunta na Universidade Federal do Amapá - Campus Binacional do Oiapoque. Trabalha questões relacionadas ao ensino de literatura na escola, literatura e reescrita e estudos da tradução, principalmente tradução colaborativa na Internet. Seu e-mail é fsfreis@yahoo.com.br.

** Professora de literatura portuguesa da Universidade Federal do Pará e do Programa de Pós-Graduação em Letras (PPGL/UFPA), onde desenvolve pesquisa sobre poesia contemporânea e tradução. Seu e-mail é izabelaleal@gmail.com.

${ }^{* * *}$ Professora catedrática de estudos iberoamericanos, comunicação intercultural e tradução na Universidade de Antuérpia (Bélgica). É doutora em Antropologia Social e Cultural pela Universidade Católica de Leuven. É autora dos livros Ni una gota de sangre impura. La España inquisitorial y la Alemania nazi cara a cara (2006), Perpetuum Mobile. Entre la balcanización y la aldea global (2004) e Etnogénesis y etnicidad en España (1998). Seu e-mail é christiane.stallaert@uantwerpen.be.
} 
history of translation in Western and non-Western cultures, it gains new dimensions in the digital era. Two fanfictions, Palavras com Estranhos (in the original, Words with Strangers, by Nolebucgrl, a fanfiction author) and Palavras com Amigos (Words with Friends, by the same author),translated by an online group of 33 Brazilian translators reveal some features of the process of collaborative translation on the Internet. The research reveals the collective character of the online translation practiced by nonprofessional female translators. Our analysis highlights the chainwork of such a practice, the interaction between translators and readers, and the process singled out by this dual interaction on one hand, between translators themselves and, on the other hand, between translator and reader.

Keywords: Fanfictions; collaborative translation; online translation.

\section{Tradução colaborativa}

De uma forma geral, a tradução colaborativa é definida como um processo em que dois ou mais agentes cooperam no trabalho de passar uma obra de uma língua para outra. No artigo "Collaborative Translation" publicado no Handbook of Translation Studies (2011), Sharon O'Brien distingue três categorias básicas quanto a essa modalidade de tradução. A primeira seria a colaboração entre dois ou vários tradutores, uma das práticas documentadas mais antigas na área da tradução. O exemplo citado por O’Brien (2011) nesta categoria é a Septuaginta, a tradução da Bíblia do hebraico para o grego realizada por setenta e dois sábios judeus. Uma segunda categoria de tradução colaborativa envolve a colaboração entre tradutor e autor, como no caso da tradução para o italiano da obra Grande Sertão: Veredas, em que João Guimarães Rosa acompanhou e analisou as traduções de sua obra junto ao tradutor Edoardo Bizzarri. A colaboração pode ser observada através da correspondência trocada entre os dois entre 1959 e 1967. Apesar de as cartas não apresentarem aos leitores trechos completos ou demais interferências do autor nas traduções, a correspondência permite entender de que forma Rosa colaborava com o tradutor Bizzari (FANTINATTI, 2009). Mais recentemente, um terceiro tipo de tradução colaborativa passou a ser frequente em comunidades virtuais e por empresas como Facebook e Wikipédia em tarefas online com o uso de tecnologias e programas para acelerar o processo de tradução, podendo também ser chamada de tradução em comunidade (O’BRIEN, 2011).

A tradução colaborativa é uma prática atualmente comum na Internet, principalmente em comunidades dedicadas à legendagem de filmes, seriados e livros recém-lançados. O crescimento desta prática obriga teóricos e estudiosos da tradução a repensarem o paradigma ocidental, consolidado no decorrer do século XX, centrado na individualidade e profissionalização do tradutor moderno. As mudanças que a era digital possibilita no hábito do tradutor ocidental conduzem a (re)criar, no contexto ocidental contemporâneo, hábitos alternativos, sejam históricos ou 'exóticos' (TYMOCZKO, 2006).

$\mathrm{Na}$ história da tradução no Ocidente a prática colaborativa perdeu-se com o tempo, devido, em parte, ao sistema de mecenato. Lefevere explica em Tradução, 
Reescrita e Manipulação da Fama Literária (2007) que os reescritores, como o autor se refere aos tradutores, tinham que se adaptar às ideologias dos mecenas para poderem receber seu pagamento, mesmo que tivessem que restringir a forma e o conteúdo do texto nessas relações de poder. Percebe-se que, por conta desses "pagamentos", o trabalho de tradução tornou-se uma atividade mais individualizada além de mais "profissional". Observa-se aqui como a individualização da prática da tradução está ligada a uma crescente profissionalização.

Em outras culturas, porém, o trabalho colaborativo se manteve como prática frequente na tradução. Eva Hung, no artigo intitulado "And the Translator is..." (2006), aponta que, no caso da China, a cooperação entre dois ou mais tradutores é uma prática estabilizada, recorrente, realizada entre pessoas creditadas como tradutores, professores, escrivães e editores.

O detalhamento do trabalho colaborativo numa cultura não ocidental apresentado por Hung (2006) permite fazer uma relação com duas das oito principais críticas ao eurocentrismo nos Estudos de Tradução que Maria Tymoczko aborda em "Reconceptualizing Western Translation Theory - Integrating Non-Western Thought about Translation" (2006). A primeira delas refere-se ao pressuposto, na tradição ocidental, de os tradutores terem uma qualificação profissional baseada numa formação ou treino específico na área ${ }^{1}$, mesmo que este fato não corresponda à realidade, pois mesmo em culturas ocidentais nem todos os tradutores foram formalmente treinados para a profissão. Outro pressuposto apontado por Tymoczko é a ideia, na cultura ocidental, de que a tradução é um trabalho individual $^{2}$, como dito antes, uma das heranças do sistema do mecenato e que não reflete de todo a realidade.

Se os pressupostos da individualidade e do profissionalismo nunca puderam dar conta da totalidade das práticas tradutórias na tradição ocidental, a tecnologia e os meios digitais deram mais relevância aos hábitos alternativos que se afastam do modelo consagrado. Neste artigo pretendemos analisar, através do caso das traduções de fanfiction, certas práticas de tradução coletiva não profissional praticadas online. Os resultados desta análise são retratados num corpus de duas fanfictions traduzidos do inglês para o português.

O corpus estudado, composto por duas traduções de fanfictions, Palavras com Estranhos (no original, Words with Strangers, de Nolebucgrl, uma autora de fanfictions) e Palavras com Amigos (Words with Friends, da mesma autora), consiste em duas histórias traduzidas em forma colaborativa e disponibilizadas na Internet. Ele permite observar o trabalho em cadeia das tradutoras, as dinâmicas do próprio grupo que se expande ou retrai em função das respostas solicitadas pelo público-leitor, as interações entre tradutoras e leitores, a divisão do trabalho entre tradutoras e revisores, além da grande capacidade que essas comunidades de tradutoras têm de organizar e reestruturar o trabalho de acordo com o tempo disponível ou com as exigências dos leitores. Claramente divergente em relação ao paradigma das práticas tradutórias idealmente apregoado de uma perspectiva mais conservadora dos Estudos da Tradução, as práticas de tradução colaborativa não profissional analisadas neste artigo mostram o vigor e a grande plasticidade dos novos hábitos surgidos na era digital. 


\section{Traduzir na era digital}

Desde o final do século XX e primeiras décadas do XXI, a Internet, além de modificar as fronteiras entre homem e máquina, mundo real e virtual, literatura e ciberliteratura, tornou-se o espaço onde também foi modificada a ideia do tradutor como profissional que trabalha de forma individual. A Internet e os meios digitais transformaram o trabalho do tradutor num trabalho colaborativo, seja através da colaboração indireta por programas de tradução online como Google Translator, Worldlingo, Déjà-Vu e o My Memory criados para auxiliar a tarefa humana, seja pelo trabalho em equipe, como no caso das grandes empresas e corporações que empregam pessoas, mesmo não sendo profissionais, para realizarem traduções em grupo, de forma a atender à demanda do mercado, fenômeno conhecido como "crowdsourcing" (O'BRIEN, 2011). Foi mediante crowdsourcing que o Facebook realizou em 2008 a tradução da rede social para o espanhol, empregando colaboradores para ajudar na tarefa coletivamente. Outro exemplo de tradução coletiva e colaborativa em Internet seria a Wikipédia:

A Wikipédia é um exemplo de esforço de tradução colaborativa sem fins lucrativos, com 3,5 milhões de artigos em inglês e 262 edições em língua estrangeira até hoje, sendo estas últimas criadas por um empenho de tradução colaborativa em crowdsourcing. Aqueles que colaboram nesses projetos são geralmente motivados por rankings virtuais (a pessoa que mais contribui e/ou realiza as melhores traduções é a mais bem avaliada) (O’BRIEN, 2011, p. 18, tradução e grifos nossos) ${ }^{3}$

Uma das consequências da tradução colaborativa em crowdsourcing é a qualidade insatisfatória dos textos traduzidos, já que as pessoas que participam do projeto não são profissionais da área. A solução encontrada pelas empresas foi exigir a presença de editores e revisores.

Enquanto o serviço humano de tradução pode demorar dias, meses ou anos, a resposta imediata por trás de um simples botão de "traduzir" na tela do computador é outro ponto positivo aos olhos dos usuários, pois surge um texto traduzido online em poucos segundos e passível de revisão através da Internet. Algumas empresas e usuários preferem trabalhar ou usar este novo espaço como reflexo da funcionalidade dos tempos modernos: os manuais de produtos importados, cuja leitura precisava ser acompanhada de um dicionário, agora estão disponíveis em formato eletrônico em um website totalmente traduzido:

Produto e serviço de informação têm sido um dos mercados tradicionais para a tradução e agora está cada vez mais disponível online. Em alguns casos, tais informações podem ser disponibilizadas somente online, uma vez que poupam os custos de distribuição e impressão físicas do documento em papel. Isto significa que as traduções de brochuras, manuais e livros de diversas áreas estão agora disponíveis em formato eletrônico. De forma parecida, alguns dos jornais e revistas de maior circulação no mundo, publicados online, estão disponíveis na web em diversas línguas. 
Diferente das versões impressas, essas edições online estão sujeitas a atualizações regulares e frequentes, o que também precisa estar refletido nas versões traduzidas. O tempo disponível para a tradução tornou-se, portanto, mais curto em alguns casos. Ademais, os leitores das publicações online podem lê-las na tela ao invés de no papel, pelo menos inicialmente (O’HAGAN \& ASHWORTH, 2002, p. 9-10, tradução nossa) ${ }^{4}$.

As novas práticas de tradução automática e crowdsourcing realizadas por fãs aparecem também em tradução de fanfiction, livros, filmes e videogames. Para saber como essas atividades são desenvolvidas, é necessário entender a organização e interação dos fãs em grandes comunidades virtuais, conhecidas como fandoms, e o que essas pessoas desenvolvem nesse meio.

\section{A cultura de fãs}

Os fanfictions surgiram como uma das atividades praticadas dentro de fandoms, grandes comunidades formadas por fãs. Matt Hills (2002) define um fã como

[...] alguém que é obcecado por uma estrela, uma celebridade, um filme, um programa de tevê, banda, alguém capaz de produzir esferas de informações sobre o assunto do fandom; consegue inclusive citar suas falas favoritas ou trechos de canções, capítulos e versos. Fãs são frequentemente bem articulados; interpretam textos midiáticos de formas variadas, interessantes e, porventura, inesperadas. Fãs participam de atividades comunitárias - são socialmente atomizados ou leitores/telespectadores isolados (HILLS, 2002, p. 7, tradução nossa) $)^{5}$.

O fã se une virtualmente ou não a outros seguidores, também fãs do produto que ele aprecia, formando os famdoms, e juntos vão se organizar em eventos, comprar produtos, discutir ideias e produzir novos gêneros que serão distribuídos, muitas vezes, na web. Hills (2002) fala de uma cultura de fã, uma nova categoria que é observada por diversos ângulos dentro da indústria cultural, levandose em consideração tanto as relações sociais - o que implica saber onde vivem e o que fazem as pessoas envolvidas -, como o retorno financeiro que trazem às distribuidoras. A dificuldade de se definir o termo advém do escasso interesse outorgado pela academia ao fenômeno, tendo em conta que as preferências dos fãs geralmente estão mais próximas da cultura popular (best-sellers, seriados ou sagas de filmes) e, portanto, mais distantes do cânone acadêmico:

Todo mundo sabe, obviamente, o que é um fã, mas num estudo acadêmico que trata da cultura de fã e abrange o problema da cultura midiática, o leitor ainda deve esperar uma definição mais "teórica" do que é um fandom, bem como que constitui uma cultura de fã. Com efeito, será que nossas noções de senso comum sobre fandom não podem ser deixadas de lado pela necessidade de um rigor acadêmico e claridade conceitual? (HILLS, 2002, p. ix, tradução nossa) $)^{6}$. 
Henry Jenkins explica em Textual Poachers (1992) que os fãs de um produto da indústria cultural se reúnem e constroem novas histórias para estender o contato com o universo ficcional. Dentro dessas práticas encontra-se a produção das fanfictions (histórias em prosa), fanzines (quadrinhos) e, atualmente, os fanfilms (curtas ou longas metragens produzidas por fãs), todas baseadas nas histórias originais, escritas e elaboradas mesmo sem autorização dos autores originais e produtores.

\section{A tradução de fanfiction}

Na era digital e no caso das traduções de fanfiction, as críticas de Tymoczko (2006) aos pressupostos do paradigma ocidental da tradução ganham mais relevância. Tanto a escrita quanto a tradução dessas ficções são realizadas por comunidades de fãs e a colaboração é uma característica inerente a diversos meios e mídias na Internet, principalmente em relação ao lançamento de legendas para seriados e filmes. Quanto a livros, quando não existe previsão de lançamento no país, os fãs se disponibilizam a traduzir e fazer a distribuição em redes sociais como Twitter e Facebook ou em sites de armazenamento em nuvens como Google Drive, Dropbox ou Minhateca. O’Brien (2011) explica como funciona esse tipo de colaboração e distribuição que se tornou comum e reconhecida, o que pode ser observado facilmente dentro da fan culture:

Mais recentemente, o desenvolvimento tecnológico tem sido um agente para a tradução colaborativa em massa: primeiro vieram as comunidades virtuais via Internet. Posteriormente, testemunhamos a digitalização de produtos e conteúdos, bem como conexões em banda larga onipresentes, os quais têm facilitado a colaboração em massa (O'BRIEN, 2011, p. 11, tradução nossa $)^{7}$.

A Internet funciona como facilitadora desse processo de tradução colaborativa no espaço virtual que envolve fatores muito mais dinâmicos do que no espaço real. Fanfictions traduzidos são encontrados comumente em websites como Fanfiction.Net, em diversas línguas - do inglês para o português ou espanhol ou francês, do francês para o espanhol, do espanhol para o português e vice-versa - em trabalhos individuais ou coletivos. Nos dois casos as traduções só são possíveis se autorizadas pelo ficwriter, a pessoa que escreveu o fanfiction.

O estímulo para se iniciar o processo de tradução colaborativa online de fanfiction é, geralmente, a não-publicação mais imediata de um livro ou o episódio inédito de um seriado. Isso gera um movimento dentro da comunidade de fãs, que imediatamente procura uma solução - traduzir em poucas horas o livro ou o episódio de seriado que ainda não chegou ao país. A respeito disso, O’Brien (2011) continua:

A tradução colaborativa está em evidência também em gêneros culturais e populares tais como videogames, produtos audiovisuais e ficção, as motivações para isso são identificadas como um desejo de preencher uma 
lacuna na publicação (quando, por exemplo, um produto não está disponível numa língua específica) ou superar o tempo de espera que pode ocorrer entre a publicação do original e a versão numa determinada língua-alvo. As pessoas podem também querer colaborar num projeto de tradução para ganhar experiência, desenvolver novas habilidades, contatos ou simplesmente querer dar algo à comunidade (O'BRIEN, 2011, p. 13 , tradução nossa) $)^{8}$.

Destaca-se, no final da citação, os motivos que levam à tradução colaborativa nas comunidades de fãs. De forma geral, a autora cita três fatores que desencadeiam esse tipo de trabalho. O primeiro deles é o fator comercial, frequente nas relações entre empresas e um grupo de tradutores que precisam lidar com um conteúdo grande a ser traduzido diante de um determinado prazo para entrega do produto (neste caso, o texto traduzido). O segundo fator seria o social, com o trabalho colaborativo voltado para alguma causa importante ou que beneficie a sociedade. O terceiro seria o pessoal, com tradutores se voluntariando para dar algo à comunidade, ou simplesmente adquirir experiência (O'BRIEN, 2011, p. 14). Nota-se, neste ponto, como os fatores social e pessoal estão relacionados. Um exemplo bastante recente, o livro Grey, de E. L. James, mesma autora de Fifty Shades of Grey, foi lançado em 18 de junho de 2015 no Reino Unido. O grupo Intrínseca, editora brasileira detentora dos direitos de tradução e de distribuição no país, lançou o livro em setembro, três meses depois da edição inglesa. Por conta da demora, alguns fãs decidiram não esperar e já traduziram em pouco mais de uma semana o livro e o distribuíram pela Internet, solucionando o atraso para aqueles leitores que não sabem ler inglês ou que não poderiam comprar um exemplar importado nas livrarias nacionais?.

\section{O perfil das tradutoras de fanfictions}

Para entendermos as práticas de comunidades de tradutores, selecionamos como corpus um perfil dedicado a traduções da Saga Crepúsculo, da autora americana Stephenie Meyer, e duas histórias traduzidas, Palavras com Estranhos (no original, Words with Strangers, de Nolebucgrl) e Palavras com Amigos (Words with Friends, da mesma autora), ambas disponíveis no Fanfiction.Net. O grupo Pervas Place 10, com 24 histórias publicadas e inúmeras outras traduções paralelas que circulam na Internet não oficialmente, foi o responsável por fazer a tradução do inglês para o português.

Quanto à análise de um corpus presente na Internet, em Métodos de pesquisa para Internet (2011), Fragoso, Recuero e Amaral ressaltam que a Internet pode ser tanto objeto, quanto local e/ou instrumento de pesquisa, e que os objetos e relações sociais construídos na virtualidade são essencialmente complexos e efêmeros, mas extremamente transparentes e acessíveis de serem observados, observação que foi confirmada no nosso estudo.

O referido grupo foi criado em 25 de setembro de 2009 e até 2015 permaneceu ativo. Era formado por 33 tradutoras11, duas beta-readers - as revisoras que corrigem e "aprovam" a publicação da história ou do capítulo - e inúmeras 
colaboradoras anônimas que são citadas ocasionalmente nas notas finais dos capítulos das traduções publicadas. No mesmo perfil, é possível ver quem traduziu cada história publicada em duas seções: "traduções completas" e em "andamento", somando 24 histórias publicadas.

Para evidenciar como as tradutoras trabalharam, as duas últimas histórias atualizadas no perfil servirão como exemplo. Palavras com Estranhos foi traduzida de 29 de junho de 2012 até 25 de abril de 2014. A história é narrada sob o ponto de vista do ator de cinema Edward Cullen que encontra, por meio do jogo online Words with Friends, a estudante da Universidade de Washington Isabella "Bella" Swan. A outra história, Palavras com Amigos, relata os mesmos fatos da primeira, mas sob a perspectiva de Bella. As informações sobre quem traduziu e a autorização da autora da obra original estão presentes na nota de apresentação que aparece no primeiro capítulo de cada história.

As traduções começaram a ser publicadas com duas semanas de diferença e foram concluídas no mesmo dia. O grupo organizou as atualizações de forma que os leitores tivessem os capítulos online uma vez por semana até a finalização. Palavras com Estranhos teve apenas duas tradutoras e um capítulo traduzido por uma terceira pessoa. A tabela 1 apresenta as tradutoras e revisoras:

Tabela 1: Tradutoras de Palavras com Estranhos (2014)

\begin{tabular}{|l|l|l|}
\hline Capítulo & Tradutora (abreviatura) & Revisora (Beta-reader) \\
\hline $1-3$ & Irene Maceió (IM) & Ju Martinhão \\
\hline $4-49$ & Ju Martinhão (JM) & Irene Maceió \\
\hline 50 & Nai (N) & (sem indicação) \\
\hline $51-52$ & Ju Martinhão (JM) & Irene Maceió \\
\hline
\end{tabular}

Fonte: Fanfiction 'Palavras com Estranhos' - disponível em <https://www.fanfiction. net/s/8267611/1/Palavras-com-Estranhos-by-Nolebucgrl/>. (2017)

A tabela 1 mostra que houve a colaboração entre duas pessoas num esquema semelhante ao que Hung (2006) apresentou, um dos tipos mais comuns de colaboração. Neste caso, IM e JM trabalham juntas e revezam os postos como tradutora e revisora. Nota-se, também, a alternância entre as tarefas de tradução e revisão, tarefas que podem ser assumidas simultaneamente pelas mesmas colaboradoras do grupo. Assim, embora tenha iniciado a tradução de Palavras com Estranhos, IM deixou a tarefa para se dedicar à revisão enquanto também traduzia e revisava outra história, Palavras com Amigos, o que justifica sua ausência ao longo da publicação semanal, enquanto JM assumiu o trabalho. Não se observa mudanças significativas com relação à presença de outras tradutoras, com exceção do capítulo 50. Em contrapartida, o grupo se expande em Palavras com Amigos, que possui dez capítulos a mais. A história foi originalmente escolhida por Irene Maceió para ser traduzida, pessoa também responsável por pedir a autorização da autora e receber e revisar a história, informações que podem ser comprovadas pelas notas iniciais e pela Nota da Tradutora (NT), também no primeiro capítulo (figura 1): 
Nota da Irene: Surpresa! Que quinta feira mais linda! Esse post está sendo feito em homenagem a nossa parceira maravilhosa, Lary Reeden. Que tem nos ajudado muito e que está fazendo aniversário hoje. Você é demais lindona!

Espero que gostem de nossas novas fics (sim, serão 2, essa POV Bella e a POV Ed que não seguirá a mesma sequencia de postagem, será bônus) Então sim, essa fic está me enlouquecendo, várias leitoras me indicaram e eu a li quase toda. As duas estão finalizadas. O POV Ed será postado separado com o nome "Words with strangers" (Palavras com Estranhos). Mas a autora fez os capítulos dele resumindo vários capítulos dos da Bella, então só começaremos o POV Ed depois do terceiro capítulo da Bella. Parece confuso, mas é simples.

Outra coisa: Para diferenciar os textos de Bella e do Esqueleto17, colocaremos os dele em Negrito e Itálico e os dela em 'Itálico'. Certo?

Curtam e nos deixem recadinhos fofinhos. Adoramos todos! Beijos

Figura 1: Nota da Tradutora no primeiro capítulo. Fonte: Fanfiction.Net (2015)

Tabela 2: Tradutoras de Palavras com Amigos (2014)

\begin{tabular}{|c|c|c|}
\hline Capítulos & Tradutora(s) & Beta-reader \\
\hline $1-9$ & Irene Maceió & Ju Martinhão \\
\hline $10-20$ & Ju Martinhão & Irene Maceió \\
\hline 21 & Carol Capelani & Irene Maceió \\
\hline 22 & NaiRobsten (Naiana) & Irene Maceió \\
\hline 23 & Carol Capelani & Irene Maceió \\
\hline 24 & Laysa Melo & Irene Maceió \\
\hline 25 & Carol Capelani & Irene Maceió \\
\hline 26 & Mônica Kurkiewicz & Irene Maceió \\
\hline 27 & NaiRobsten & Irene Maceió \\
\hline 28 & Mônica Kurkiewicz & Irene Maceió \\
\hline 29 & Carol Capelari & Irene Maceió \\
\hline 30 & NaiRobsten & Irene Maceió \\
\hline 31 & Mônica Kurkiewicz & Irene Maceió \\
\hline 32 & Carol Capelari & Irene Maceió \\
\hline 33 & NaiRobsten & Irene Maceió \\
\hline 34 & Mônica Kurkiewicz & Irene Maceió \\
\hline 35 & Carol Capelari & Irene Maceió \\
\hline 36 & NaiRobsten & Irene Maceió \\
\hline 37 & Mônica Kurkiewicz & Irene Maceió \\
\hline 38 & Carol Capelari & Irene Maceió \\
\hline 39 & Nai (deixa de assinar como NaiRobsten) & Irene Maceió \\
\hline 40 & Irene Maceió & Ju Martinhão \\
\hline 41 & Carol Capelari & Irene Maceió \\
\hline 42 & AnnaP (substituindo Nai) & Irene Maceió \\
\hline
\end{tabular}




\begin{tabular}{|l|l|l|}
\hline 43 & $\begin{array}{l}\text { Laysa Melo (substituindo Mônica Kurkie- } \\
\text { wicz) }\end{array}$ & Irene Maceió \\
\hline 44 & Carol Capelari & Irene Maceió \\
\hline 45 & Nai & Irene Maceió \\
\hline 46 & $\begin{array}{l}\text { Ju Martinhão (substituindo Mônica Kurkie- } \\
\text { wicz) }\end{array}$ & Irene Maceió \\
\hline 47 & Carol Capelari & Irene Maceió \\
\hline 48 & Nai & Irene Maceió \\
\hline 49 & $\begin{array}{l}\text { Laysa Melo (substituindo Mônica Kurkie- } \\
\text { wicz) }\end{array}$ & Irene Maceió \\
\hline 50 & Carol Capelari & Irene Maceió \\
\hline 51 & Nai & Irene Maceió \\
\hline 52 & $\begin{array}{l}\text { Ju Martinhão (Mônica Kurkiewicz deixa } \\
\text { oficialmente a equipe) }\end{array}$ & Irene Maceió \\
\hline 53 & Carol Capelari & Irene Maceió \\
\hline 54 & Nai & Irene Maceió \\
\hline 55 & Ju Martinhão & Irene Maceió \\
\hline 56 & Carol Capelari & Irene Maceió \\
\hline 57 & $\begin{array}{l}\text { AnnaP e Ju Martinhão (antecipa a vez de } \\
\text { traduzir) }\end{array}$ & Irene Maceió \\
\hline 58 & LeiliPattz (substuindo Nai) & Irene Maceió \\
\hline 59 & Carol Capelari & Irene Maceió \\
\hline 60 & Nai & Ju Martinhão \\
\hline $61-62$ & cadón \\
\hline
\end{tabular}

Fonte: Fanfiction "Palavras com Estranhos" - Disponível em: <https://www.fanfiction. net/s/8267611/1/Palavras-com-Estranhos-by-Nolebucgrl/>. (2017)

É possível notar na tabela 2 que, para manter o cronograma de atualização de histórias e não perder o interesse do leitor, que "abandona" ou "cobra" o capítulo em caso de atraso, as tradutoras se organizam numa "colaboração em cadeia" para não sobrecarregar uma única companheira. O grupo tenta seguir uma sequência que fica mais evidente a partir do capítulo 21, quando três tradutoras e algumas colaboradoras se revezam nas traduções dos capítulos. O posto de beta-reader permanece constante, com poucas ou quase nenhuma alteração nas duas traduções. Cada capítulo possui o nome da tradutora (às vezes dois nomes aparecem, como se observa no capítulo 57) e a nota da revisora. Esse tipo de organização sugere que em histórias longas as tradutoras dividem os capítulos entre si e se comprometem a entregá-los dentro de certo prazo para a revisão pela beta-reader e posterior publicação na Internet. Caso a tradutora não consiga cumprir a tarefa, outra pessoa a substitui imediatamente para que não haja capítulos atrasados, além de entrar em contato com os leitores e assinar as notas.

É importante ressaltar que as NT e Notas da Beta (NB) apresentam normalmente as informações a respeito do tempo de publicação e da identidade das tradutoras. Dois pontos são importantes de destacar: a questão da falta de formação profissional dos tradutores voluntários, uma das críticas mais frequentes em relação à atividade dos fãs, e o tempo dedicado à tradução e à publicação 
dessas histórias. Existe um prestígio profissional que advém do compromisso assumido com a tradução das histórias, criando um outro fandom, pois os leitores ou outros usuários vão atrás do material que o grupo produz e tentam se manter fiéis e pacientes a tudo que esse grupo de tradutores lança.

Os indícios sobre a falta de formação e o treinamento profissional das tradutoras estão presentes nas NT e NB de vários capítulos. A partir de informações fornecidas pelo próprio grupo, é possível diferenciar as atividades profissionais dessas tradutoras da atividade de tradução de fanfictions, que elas desempenham como uma espécie de hobby, como pode ser observado nas figuras 2 , 3 e 4 . Sobre a formação técnica dessas tradutoras, sabe-se apenas que traduzem de forma espontânea, mas nota-se que, uma vez que são parte do grupo de tradutoras, assumem o compromisso de forma profissional - traduzindo, editando e revisando o texto, adicionando notas de tradução, respondendo aos comentários dos leitores -, mesmo sem ter formação técnica na área ou remuneração financeira. As notas, neste caso, revelam a importância que tem para elas a interação e o 'feedback' dos leitores. As tradutoras incitam os leitores para que escrevam o que acharam do trabalho e do enredo em forma de comentários (reviews), presentes no perfil do texto traduzido e que podem ser visualizados por todos que tenham interesse em começar a ler.

\section{Nota da Irene:}

Hum, queria ter tido um "amigo virtual" assim. E ah, Edward? Sério? HUm, queria muitooooo que ele falasse comigo, mas vamos cair na real "cof cof* e deixar reviews! Kkkk...

COmo avisei em "A Submissa" estarei viajando até quinta feira que vem e possivelmente algumas fics sofrerão atrasos. Me perdoem, mas é uma viagem a trabalho e nem sempre consigo ter forças pra ficar acordada a noite no hotel pra postar.

Figura 2: NT do capítulo 8. Fonte: Fanfiction.Net (2015)

\section{Nota da Irene:}

Meninas, a Ju está viajando, por isso não teremos PcE até ela voltar dia 25/07. Bem, vou tentar manter PcA atualizada. Corro contra o tempo betando... mas não fiquem chateadas caso eu não consiga. Estou atolada com as férias do meu chefe, mas estou tentando. Desculpem os possíveis erros. Beijos.

Figura 3: NT do capítulo 38. Fonte: Fanfiction.Net (2015)

Nota da Irene: Mais uma vez a Lay me salvou. Gente, em novembro e dezembro fico com a empresa na minha responsabilidade e até postar capítulos depende da sorte... pq fico pra lá e pra ca'. Então de 3 em 3 semanas (que seriam os meus capítulos) vou precisar da compreensão de vcs. Beijos e assim que a Ju terminar o de PcE posto por aqui. Ela tbm está correndo no trabalho. $=$ * 
Nota da Irene:

Aha! E agora somos um trio! Carol Capelari, NaiRobsten e Irene. Uhu! E Ju como beta. Um quatrilho! Hahahahahah

Bem meninas, a fic está chegando nas partes que mais queríamos... espero que estejam gostando. $=D$

Desculpem por ontem não ter postado, mas acabou que IWFYITD ficou pra quarta que vem. $=p$

Beijos e até amanhã em "Minha Linda Tempestade".

Figura 5: NB do capítulo 22. Fonte: Fanfiction.Net (2015)

Nota da Irene: Nussa... que calor. $=D$

Gente, estamos com probleminhas tecnicos na nossa equipe, mas hoje a AnnaP nos ajudou. Amém, obrigada! Semana que vem seria o capítulo da Monica, e ela tbm não está respondendo... e no lugar de PcA na próxima quarta postarei o capítulo de EeOPeM, para me dar tempo de traduzir o capítulo. A Ju irá postar o de PcE... então no fds eu posto e arrumo tudo.

Hoje vamos receber mais um capitulo de Now and Then, pq sexta não estarei por aqui. $E$ amanhã a Ju irá postar PcE. Espero vcs. $=D$

Figura 6: NB do capítulo 42Fonte: Fanfiction.Net (2015)

As notas revelam também outro aspecto da dinâmica do grupo quanto à tradução colaborativa (Fig. 5, 6 e 7), a saber, a rapidez da reorganização do trabalho em função da disponibilidade de cada tradutora, como, por exemplo, quando uma delas ocupa a posição de tradutora do capítulo da semana no momento em que outra pessoa está indisponível para o serviço. Além disso, novas tradutoras surgem ao longo da publicação, desenvolvendo assim o esquema da tradução em "cadeia", já citado anteriormente: a equipe se organiza de forma que cada pessoa seja responsável por um capítulo de três em três semanas, um esquema que tenta ser seguido mesmo quando os problemas pessoais e profissionais impedem a atualização semanal. Essas comunidades são flexíveis e dinâmicas, resolvem problemas com rapidez, substituindo imediatamente quem não pode cumprir a tarefa - o que demonstra capacidade de reagir diante de imprevistos, como também acontece no mundo do trabalho real.

\section{Considerações finais}

Neste artigo analisamos algumas práticas de tradução coletiva na era digital, focadas no gênero da literatura de fanfiction. A tradução colaborativa na Internet realizada por fãs continua a crescer por conta dos inúmeros benefícios que as comunidades encontram: rapidez das informações através das redes sociais, acesso mais fácil a plataformas de busca, economia para os usuários que podem encontrar mídias de graça e evitar o preço praticado pelas distribuidoras. Livros, 
filmes e seriados são apenas alguns exemplos do que grandes comunidades podem produzir e distribuir sem necessidade de cobrar pelo serviço, com empenho e incentivo de outros fãs. Cada atividade parece atrair mais pessoas para trabalhar, mesmo que sem formação na área. Em relação às traduções coletivas de fanfictions, nota-se uma organização nas tarefas que resulta em um aceleramento no processo de tradução.

A partir dum corpus de duas fanfictions traduzidas do inglês para o português, estudamos algumas práticas e estratégias desenvolvidas por um grupo de tradutoras femininas não profissionais no Brasil. O corpus estudado permite observar o trabalho em cadeia das tradutoras, as dinâmicas do próprio grupo que se expande ou retrai em função das respostas solicitadas pelo público-leitor, as interações entre tradutoras e leitores, a divisão do trabalho entre tradutores e revisores, além da grande capacidade que essas comunidades de tradutoras têm de organizar e reestruturar o trabalho de acordo com o tempo disponível ou com as exigências dos leitores. Claramente divergente em relação ao paradigma das práticas tradutórias idealmente apregoado pelos Estudos de Tradução ocidentais no século XX, as práticas de tradução colaborativa não profissional analisadas neste artigo mostram o vigor e a grande plasticidade dos novos hábitos surgidos na era digital.

Notes

1. Esta é a quinta crítica apresentada por Tymoczko, que posteriormente desmitifica: "Translators are generally educated in their art and they have professional standing; often they learn their craft in a formal way, connected with schooling or training that instructs the translator in language competence, standards of textuality, norms of transposition and so forth" (p. 18).

2. A autora comenta: "the process of translation is a sort of "black box": an individual translator decodes a given message to be translated and recodes the same message in a second language" (p. 18).

3. No original: "Wikipedia is an example of a not-for-profit collaborative translation effort, with 3.5 million articles in English and 262 language editions to date, the latter of which have been created through a crowdsourced collaborative translation effort. Those who collaborate on crowdsourced translation projects are often motivated via leaderboards (the person who contributes the most and/or best translations is rated most highly)".

4. No original: "Product and service information has been one of the traditional markets for translation and is now being increasingly made available online. In some cases, such information may be available only online since this saves the physical printing and distribution costs of the paper-based documentation. This in turn means the translations of product brochures, manuals or PR literature are now also published in electronic mode. Similarly, some of the world's major daily newspapers and magazines, which are published online, are often made available on the Web in a number of languages. Unlike printed versions, these online editions are subject to regular and frequent updates, which need to be reflected also in the translated versions. The time available for translation has therefore shortened in some cases. Also, the readers of online versions of publications may read them on screen rather than on paper, at least initially".

5. No original: "[...] somebody who is obsessed with a particular star, celebrity, film, TV programme, band, somebody who can produce realms of information on their 
subject of fandom, and can quote their favoured lines or lyrics, chapter and verse. Fans are often highly articulate. Fans interpret media texts in a variety of interesting and perhaps unexpected ways. And fans participate in communal activities - they are socially atomised or isolated viewers/readers".

6. No original: "Everybody knows what a fan is, of course, but in an academic study dealing with fan cultures and covering the issue of cult media, the reader might still expect a "theorised" definition of what fandom is, and what contitutes a fan cult. Surely our common sense notions of fandom cannot be left untouched by the need for academic rigour and conceptual clarity?"

7. No original: "More recently, technological developments have acted as a driver for mass collaborative translation: First came the creation of virtual communities via the Internet. Then we witnessed the digitization of products and content and ubiquitous broadband connections, all of which have enabled mass collaboration".

8. No original: "Collaborative translation is also in evidence in cultural and popular genres such as games, audio-visual products and fiction, the motivators for which are identified as a wish to fill a gap in publication (when, for example, a product is unavailable in a particular language) or to overcome a time delay which might occur between publication of the source and a specific target language version. People may also wish to collaborate in a translation project in order to gain experience, learn new skills, network or simply to give back to the community".

9. A notícia completa pode ser lida aqui: <http://g1.globo.com/pop-arte/blog/quemcurte-o-blog-de-fa-clube/post/grey-e-traduzido-por-fas-tres-meses-antes-dolancamento-oficial-no-brasil.html/>. Acesso em: 15 nov. de 2017.

10. Ver <https://www.fanfiction.net/u/2095160/Pervas-Place>. Acesso em: 15 nov. de 2017.

11. As tradutoras se identificam no perfil como: Ju Martinhão, Irene, Illem, Leili, Mariana, Carol C, Zah, Mônica, Naiara, Laysa, Ingrid, Ana Paula Pasquim, Beatriz Vieira, Marcela, Bruna, Ninnah, Mery, Bruna M, Yerma, Thaís, Lay, Bruna Brito, Lary, Zahzuda, Maiara Turatti, Jéssica, Nate, Monikah, Vii Fortunato, Larissa Catanhede, Carol Capelari e Alexia.

\section{Referências}

"Fanfiction.net". Disponível em: <https://www.fanfiction.net/book/>. Acesso em 15 de nov. 2017.

"Fanfiction 'Palavras com Estranhos by Nolebucgrl”'. Disponível em: <https://www. fanfiction.net/s/8267611/1/Palavras-com-Estranhos-by-Nolebucgrl/>. Acesso em: 15 nov. 2017.

"Fanfiction 'Palavras com Amigos by Nolebucgrl"'. Disponível em: <https://www. fanfiction.net/s/8216657/1/Palavras-com-Amigos-by-Nolebucgrl/>. Acesso em 15 de nov. 2017.

FANTINATTI, Tatiana Arze. Mitotradução em Grande Sertão: Veredas - Enfoque Descritivo e Receptivo da Interculturalidade Ítalo-Brasileira. Tese (Doutorado) Programa de Pós-Graduação em Letras Neolatinas, Universidade Federal do Rio de Janeiro), Rio de Janeiro, 2009,

Disponível em:

$<$ http://www.letras.ufrj.br/pgneolatinas/media/bancoteses/tatianaarzefantina ttidoutorado.pdf $>$. Acesso em 15 nov. de 2017.

FRAGOSO, S.; RECUERO, R.; AMARAL, A. Métodos de Pesquisa para Internet. Porto Alegre: Editora Sulina, 2011, 240 p.

"Grey é traduzido por fãs três meses antes do lançamento oficial no Brasil". Disponível em: <http://g1.globo.com/pop-arte/blog/quem-curte-o-blog-de-fa-clube/post/ 
grey-e-traduzido-por-fas-tres-meses-antes-do-lancamento-oficial-no-brasil. html/>. Acesso em: 15 nov 2017.

HILLS, Matt. Fan Cultures. Nova York: Routledge, 2002.

HUNG, Eva. "And the Translator is..." - Translators in Chinese History. In: HERMANS, Theo (Org.).Translating Others. Manchester - UK: St. Jerome Publishing, 2006, p. 13-31.

JENKINS, Henry. Textual Poachers. New York: Routledge, 1992.

LEFEVERE, André. Tradução, Reescrita e Manipulação da Fama Literária. Tradução de Claudia Matos Seligman. Florianópolis: EDUSC, 2007.

O'BRIEN, Sharon. Collaborative Translation. In: Handbook of Translation Studies - volume 2. Amsterdam/Philadelphia: John Benjamins Publishing Company, 2011, p. 17-20.

O'HAGAN, M; ASHWORTH, D. Translation-Mediated Communication in a Digital World - Facing the Challenges of Globalization and Localization. London: Cromwell Press, 2002.

"Pervas Place". Disponível em: < https://www.fanfiction.net/u/2095160/PervasPlace/>. Acesso em 15 nov 2017.

TYMOCZKO, Maria. Reconceptualizing Western Translation Theory - Integrating Non-Western Thought about Translation. In: HERMANS, Theo (Org.). Translating Others. Manchester - UK: St. Jerome Publishing, 2006, p. 13-31.

Recebido em: 15/11/2017

Aceito em: 27/04/2018 